\title{
Experiences of Physical Activity One Year after Bariatric Surgery
}

\author{
Malin Wiklund ${ }^{1,2, *}$, Monika Fagevik Olsén ${ }^{1,2,3}$, Torsten Olbers ${ }^{3}$ and Carin Willén ${ }^{2}$ \\ ${ }^{I}$ Department of Physiotherapy and Occupational Therapy, Sahlgrenska University Hospital, Gothenburg, Sweden \\ ${ }^{2}$ Institute of Neuroscience and Physiology/Physiotherapy, Sahlgrenska Academy, University of Gothenburg, \\ Gothenburg, Sweden \\ ${ }^{3}$ Department of Surgery, Sahlgrenska University Hospital, Gothenburg, Sweden
}

\begin{abstract}
Background and purpose: Obesity is a major global health problem today and the only evidence-based method leading to a long-lasting weight reduction is bariatric surgery. Physical activity improves health, decreases the incidence of several diseases and may influence weight loss outcome after bariatric surgery. Knowledge regarding how patients experience physical activity after bariatric surgery could provide us with better tools to enhance physically active.

Methods: The aim of the present study was to describe how patients experience physical activity one year after bariatric surgery. An inductive qualitative content analysis was used to analyse semi-structured interviews with twenty-four patients one year after bariatric surgery.

Results: The main findings emerged in four overarching themes: "Hindrances of physical activity", "Physical activity with a less obese body implies achievement", "Coming to an understanding of the benefits of physical activity" and "Need of support".

Conclusion: According to our findings patients experience both achievements and hinders with regard to physical activity one year after surgery. Patients had an increased understanding of the benefits of physical activities, but support appears necessary to obtain and maintain a suitable level.
\end{abstract}

Keywords: Bariatric surgery, gastric by-pass surgery, interview, obesity, physical activity, qualitative content analysis.

\section{INTRODUCTION}

The global epidemic of overweight and obesity is a major health problem and the only evidence-based method leading to a long-lasting weight reduction is bariatric surgery [1]. In a systematic review 15 of 17 observational studies suggest that exercise is associated with greater weight loss following bariatric surgery [2]. Besides the increased weight loss effect it has also been shown that regular physical activity decreases mortality in obese persons [3]. Physical activity can furthermore result in a lower risk of cardiovascular disease, colon cancer and breast cancer [4] and has a positive effect on physical and mental health and quality of life [5]. Greater knowledge regarding how patients experience physical activity after bariatric surgery gives physical therapists better tools for guiding these patients into becoming more physically active.

The aim of physical therapy is to provide services to individuals and populations to develop, maintain and restore maximum movement and functional ability throughout their

*Address correspondence to this author at the Department of Physiotherapy and Occupational Thearphy, Sahlgrenska University Hospital, 41345 Gothenburg, Sweden; Tel: +46313429321; Fax: +46313424341;

E-mail: malin.wiklund@vgregion.se lifespan [6]. A study by Wiklund et al. [7] regarding Swedish patients' experiences of physical activity before bariatric surgery showed that the patients had both positive and negative experiences, and that support is necessary in different ways, not only to initiate physical activity, but also to maintain it. It has not yet been examined if this is also the case one-year after surgery.

This study aimed at describing how Swedish patients experience physical activity one year after bariatric surgery.

\section{METHOD}

This study is a part of a prospective two centre randomised clinical trial comparing laparoscopic Roux-en-Y gastric bypass and laparoscopic bilio-pancreatic diversion with duodenal switch in patients with a BMI $>50 \mathrm{~kg} / \mathrm{m}^{2}$, in this paper called the "clinical trial. The primary endpoint in the "clinical trial" was weight loss and weight stability over five years. A total of 60 patients were included, 30 patients from each centre. Inclusion and exclusion criteria as well as the weight outcome and metabolic effects and quality of life in the clinical trial have previously been described $[8,9]$.

These inclusion criteria were adopted in this qualitative study; 1. Patients operated at Sahlgrenska University Hospital, 2. Speaking Swedish language, 3. Mentally lucid 
Table 1. Demographic data of the included patients. Data are shown as number or median (min-max).

\begin{tabular}{|c|c|}
\hline Patients (Women/Men) & 24 (17/7) \\
\hline \hline Age (year) & $170(139-49)$ \\
\hline Height $(\mathrm{cm})$ & $57(46-79)$ \\
\hline BMI* $\left(\mathrm{kg} / \mathrm{m}^{2}\right)$, before surgery & $37(28-56)$ \\
\hline BMI* $\left(\mathrm{kg} / \mathrm{m}^{2}\right), 1$ year after surgery & $24(15 / 9)$ \\
\hline Bariatric surgery, Gastric bypass /Duodenal Switch & $2(0-6)$ \\
\hline Days/week physical activity $>30$ min, before surgery & $4(2-7)$ \\
\hline Days/week physical activity $>30$ min, 1 year after surgery & \\
\hline
\end{tabular}

* BMI = Body Mass Index

and orientated at the time of the study. Twenty-four of 30 patient eligible $(80 \%)$ accepted to participate in this study. Demographic data are presented in Table 1.

The interviews were performed one year after bariatric surgery and took place in a quiet room in the hospital where the patients could speak freely without being disturbed. The first author (MW) and a specialized nurse responsible for collecting data to the clinical trial conducted the interviews.

The interviews focused on four domains: 1. Quality of life, 2. Expectations of surgery, 3. Excess skin and 4. Physical activity. The definition of physical activity given and explained to patients before the interview were: "any bodily movement produced by skeletal muscles that result in energy expenditure" [10]. The initial question, concerning physical activity, was "How do you experience physical activity?" This question was followed by additional open questions. Each interview lasted 15-40 minutes and was tape-recorded and then transcribed verbatim.

The part of the text addressing physical activity was analysed using qualitative content analysis as described by Graneheim and Lundman 2004 using an inductive approach. Content analysis does not require an underlying theory and can be used when existing theory or research literature on a phenomenon is limited [11]. Content analysis is a method of systematically analysing text from interviews [12].

The first step in the analysis process included reading the interviews through several times to obtain a sense of the whole. Then the text regarding the patients' experiences of physical exercise was extracted and brought together into one text, which constituted the unit of analysis. The next step was to divide the text into meaning units. A meaning unit can be one or several words, sentences or paragraphs containing aspects relating to each other through their content and context. The meaning units were than condensed, while preserving their core intent, and labelled with a code.

The whole context was considered when condensing and labelling meaning units with codes. The codes were gathered and abstracted into themes and sub-themes. The first author (MW) did the first analytical and interpretation process. The underlying meaning of the condensed meaning units were analysed and discussed in an open dialogue with two of the authors (CW and MFO). Reaching agreement in this process led to identification and formulation of themes and subthemes.

Written informed consent was obtained from all patients after delivering both verbal and written information. The Regional Ethical Review Board of Gothenburg, Sweden, approved the study.

\section{RESULTS}

Four themes and six sub-themes emerged from the interviews (Table 2). The themes (capital letter), sub-themes (bold type) and their quotations (italics) are presented in the text below. Quotations from the original text are considered to be representative expressions of meaning. Codes from one interview could be present in several sub-themes and every sub-theme may have representation from one or more interviews.

\section{HINDRANCES OF PHYSICAL ACTIVITY}

Patients experienced different obstacles preventing them from being physically active. Not only the physical body was considered an obstacle but also that motivation to exercise was low and an unwillingness to expose oneself in front of others was expressed. The theme comprises three subthemes: "Physical Hinders", "Mental Hinders" and "Social Hinders"

\section{Physical Hindrances}

One year after surgery the patients still experience their physical body as a hinder stopping them from being physically active. Further weight reduction is regarded necessary before the patient can become more physically active.

"Then I will definitely do it, the less I weigh, the easier it will be to be active, yes, absolutely, so I won't say it. But I won't become a handball player or the likes, but perhaps an easier exercise class, I can imagine me doing that, yes."

The physical side effects of surgery e.g. diarrhoea and excess skin prevented patients from being as physically active as they would like to be.

"If I walk, it sets my stomach off, then I need to be near a toilet so it's much better cycling” 
Table 2. The four themes and six sub-themes and their codes, and examples of condensed meaning units and meaning units from interviewing patients one year after bariatric surgery about physical activity.

\begin{tabular}{|c|c|c|c|c|}
\hline Meaning Unit & Condensed Meaning Unit & Code & Sub-Theme & Theme \\
\hline $\begin{array}{c}\text { "It's getting there, when I am there at the } \\
\text { gym or the swimming pool, to train at the gym } \\
\text { or swim, its no problem once I'm there. But } \\
\text { getting myself there, I find loads of excuses } \\
\text { all the time." }\end{array}$ & $\begin{array}{l}\text { When I am there, at the gym or } \\
\text { the swimming pool, it's no } \\
\text { problem. But getting myself } \\
\text { there, I find excuses all the } \\
\text { time. }\end{array}$ & Excuses & $\begin{array}{c}\text { Mental } \\
\text { Hindrances }\end{array}$ & \multirow[t]{2}{*}{$\begin{array}{c}\text { HINDRANCES OF } \\
\text { PHYSICAL ACTIVITY }\end{array}$} \\
\hline $\begin{array}{l}\text { "I don't go to any swimming pool, as there is } \\
\text { so much excess skin on my arms and stomach. } \\
\text { I just can't cope with it. Swimming is } \\
\text { something that I used to do, regularly then, } \\
\text { and it felt good for my back and that. But I } \\
\text { don't do it now because of my arms." }\end{array}$ & $\begin{array}{l}\text { There is so much excess skin on } \\
\text { my arms and stomach. } \\
\text { Swimming felt good for my } \\
\text { back, but I don't do it now } \\
\text { because of my arms. }\end{array}$ & Feeling Exposed & Social Hindrances & \\
\hline $\begin{array}{c}\text { "I think that it's pleasant taking a walk and, } \\
\text { now I am the one who suggests, good God, we } \\
\text { can walk into town, which never happened } \\
\text { before I can tell you." }\end{array}$ & $\begin{array}{l}\text { It is pleasant taking a walk, } \\
\text { now I suggest we walk into } \\
\text { town, which never happened } \\
\text { before. }\end{array}$ & Pleasant feelings & $\begin{array}{c}\text { Mental } \\
\text { Achievement }\end{array}$ & \multirow[t]{2}{*}{$\begin{array}{l}\text { PHYSICAL ACTIVITY } \\
\text { WITH A LESS OBESE } \\
\text { BODY IMPLIES } \\
\text { ACHIEVEMENT }\end{array}$} \\
\hline $\begin{array}{c}\text { "Yes, my husband of course thinks that it's } \\
\text { fantastic that we can work outdoors together, } \\
\text { we have a farm, and it makes a difference, as } \\
\text { I haven't been able to help at all." }\end{array}$ & $\begin{array}{l}\text { We can work together; it makes } \\
\text { a difference, as I haven't been } \\
\text { able to help at all. }\end{array}$ & Participation & $\begin{array}{c}\text { Social } \\
\text { Achievement }\end{array}$ & \\
\hline $\begin{array}{l}\text { "I feel I need to strengthen my back and } \\
\text { stomach, as I often have a sore back, I get } \\
\text { tired, I sit a lot at my work. So, I have been } \\
\text { and tested a class called 'Core' and it's so } \\
\text { great, the physical therapist said that that } \\
\text { type of exercise would suit me as well, she } \\
\text { thought it was a good choice, as you exercise } \\
\text { using your own weight, that you don't exert } \\
\text { yourself too much." }\end{array}$ & $\begin{array}{l}\text { I have tested a class called } \\
\text { "Core", the physical therapist } \\
\text { said that that type of exercise } \\
\text { would suit me. It was a good } \\
\text { choice. }\end{array}$ & Advice & & NEED OF SUPPORT \\
\hline
\end{tabular}

"I have developed so much skin on my legs that it's tough going running”

\section{Mental Hindrances}

The patients interviewed also gave various mental obstacles that prevented them from being physically active or exercising. Motivation to exercise was low, and it was experienced to be tedious and boring exercising on their own and they found many different excuses not to exercise, for example the weather.
"It's getting there, when I am there at the gym or the swimming pool, to train at the gym or swim, it's no problem once I'm there. But getting myself there, I find loads of excuses all the time."

"But I don't like it when it's cold and windy and raining and it hasn't done much more than that."

\section{Social Hindrances}

The interviews revealed social obstacles that prevented the patients from being physically active. Exercising at the 
gym, swimming baths and other exercise complexes were not chosen because of unwillingness to expose themselves in front of others. One patient reported that her excess skin prevents her from swimming.

"I don't go to any swimming pool, as there is so much excess skin on my arms and stomach. I just can't cope with it. Swimming is something that I used to do, regularly then, and it felt good for my back and that. But I don't do it now because of my arms."

Financial reasons, was a further cause for refraining from exercising:

"I swam a lot before, but it hasn't happened. It costs money to go to the swimming baths as well."

\section{PHYSICAL ACTIVITY WITH A LESS OBESE BODY IMPLIES ACHIEVEMENT}

This theme comprised three sub-themes: "Physical Achievement", "Mental Achievement" and "Social Achievement". The patients described that it had become easier and demanded less energy to move. Positive feelings were experienced and family life was affected positively.

\section{Physical Achievement}

The patients described that it was easier to move around and that this was one great benefit of being less obese after the surgery. Physical symptoms that were earlier problems were no longer as prominent.

"I had a lot of problems with my knees and feet and so on. Now I don't have as much problem with my knees and feet."

"I walk faster; I can take longer steps and so on. And I don't get breathless either."

The ability to be active became more apparent through having more energy than previously depicted based on past experience.

"We have a route at home in the country that is four and a half kilometres and I started walking it several weeks ago and I thought, I'll walk, yes, a third of the way and then go back, but then I felt after I had walked a third that'goodness me', that was nothing and so I carried on the whole way. And that is something that was totally out of the question before."

Through an increased energy, previous surrounding obstacles are no longer an issue and it is now possible to make other everyday choices:

"I can move about much better, much suppler and much quicker. It's much easier to walk down to the shopping centre than to take the car out of the garage as I always did before."

The improved ability to perform physical activity has led to an increase in the level of daily activity and exercising:

"I: How much exercise do you do?”

“P: Much, much more. I didn't do any exercise, absolutely nothing that I didn't have to. Now I walk everywhere, I walk to where I'm going and I jump off the tram a few stops before so I can walk the rest or I don't bother about that extra tram journey. I walk instead, yes, it's not that far, but for me it is, if you compare with how far I walked before."

\section{Mental Achievement}

Physical activity did not only have positive physical effects but also affected the patient's mental status positively. The patients reported that they felt better, felt more satisfied and relieved at being able to be more physically active.

"I: How do you feel during activity?”

"P: I feel good actually, I mean I have never really understood the need for exercise before. P: 70 kilos lighter today than a year ago, it feels, there is such a big difference today compared with how it was before. I don't actually believe it; I never thought that I would experience this, this feeling that I actually feel."

"I: What feeling?"

"P: Yeah, relief that one can walk again without major problems.”

The patients experienced positive feelings during physical activity, which has in turn given them more initiative to perform activity, something that had not occurred previously.

"I: How do you feel inside when you exercise today?"

“P: I feel great, you can't...I can't say that I feel good because it's much more than good, I mean I can't find the perfect word."

"I think that it's pleasant taking a walk and, now I am the one who suggests, good God, we can walk into town, which never happened before I can tell you."

An earlier fear of injuring oneself has now changed to exercising with confidence:

"Before I walked carefully, carefully because I was frightened of falling, that I would injure myself or something. I don't need to think about that now."

\section{Social Achievement}

The interviews revealed that the patients were now more able to participate in social family activities as well as being more independent. It was evident that the patients were delighted at being able to do things together as a family and at having the energy to spend time with their children.

"I notice now that he (son) comes and asks me to do things with him, before he didn't ask as he knew that I would say no, but now he has the courage to come and say - mum do you want to do something?"

The improved physical ability has resulted in patients being more able to contribute to supporting their family financially and participating in family activities.

"Yes, my husband of course thinks that it's fantastic that we can work outdoors together, we have a farm, and it makes a difference, as I haven't been able to help at all." 
An increased level of independence in different activities was expressed.

"I'm painting at the moment, I have closed down and carried a whole load of furniture and fixed things. I fled a bit before maybe took in someone to help me, when it got particularly bad.... Now I do these things by myself."

\section{COMING TO AN UNDERSTANDING OF THE BENEFITS OF PHYSICAL ACTIVITY}

This theme illustrates that attitudes have changed resulting in increased motivation and greater understanding of the benefits of physical activity. The patients now perceive physical activity essential for achieving and maintaining further weight loss.

"It's not just that we've had an operation but you have to, it's just a small part of it, you have to think as well, I have to help myself, through food and exercising and so on."

"I'm not counting on that I will lose weight as quickly as I have during this first year, but say that I lose a further $10 \mathrm{~kg}$ this year coming, I'll be really pleased. Roughly $1 \mathrm{~kg} \mathrm{a}$ month, I believe that exercise is needed too, I have noticed that the weight doesn't disappear on its own anymore."

\section{NEED OF SUPPORT}

This theme illustrates the need of support from both friend and family and from health professionals when attempting to be physically active. The patients expressed difficulties finding a suitable level of exercise and found it beneficial getting support and help to find a suitable intensity.

"Now I got my act together and came down to the gym at work. But unfortunately I had to pay a price, my foot became swollen, almost immediately, over exertion is what it's called, felt just like packing it all in that week. But no, you have to take it easy; it's just that you are so eager in the beginning."

"I feel I need to strengthen my back and stomach, as I often have a sore back, I get tired, I sit a lot at my work. So, I have been and tested a class called 'Core' and it's so great, the physical therapist said that that type of exercise would suit me as well, she thought it was a good choice, as you exercise using your own weight, that you don't exert yourself too much."

It is important that the exercise chosen is adapted not only to the patients' level of fitness but also that it is performed in the right environment:

"Exercising, I believe is very good, like as I still weigh $90 \mathrm{~kg}$ and yes, I'm unusually stiff so you know, such as hip exercise and I think that's great and I also go to a pensioners exercise class, Everyone is really wrinkly and many are much bigger than I am and so on and then you have a little bit of faith in it"

Support and help from friends and family to get out and exercise in order to maintain a good activity level was regarded important:

"I think that I need to go and exercise with someone so that you nag a little at one another and I have a friend, we try and find one day a week anyway when we can exercise together."

"My husband likes the same things (exercising, cycling) and he encourages me and he comes along with me, and he thinks it's great fun. So it feels great to have someone."

\section{DISCUSSION}

The aim of this study was to describe how Swedish patients experience physical activity one year after major weight loss following bariatric surgery. Beside improvements in mobility our results indicate that even one year after surgery the patients still experience physical, mental and social hinders preventing them from being physically active. This might not be unique for this group, however the patients in this study might have experienced specific problems as they were still obese/overweight even after massive weight loss.

A strong association has been demonstrated between a risk of developing diseases and a lack of physical activity [13] and therefore it appears important to obtain knowledge in addressing individual hinders and challenges. Patients experienced problems due to side effects from the surgery (e.g. diarrhea, dumping or excess skin). These side effects resulted in not only physical hindrance but also social hindrance, as they for example did not want to dress in beachwear or tight exercise clothing due to excess skin. Biörserud et al. [14] have shown that excess skin causes problems with fungal infections and itching, physical unpleasantness and complicates physical activity. Patients concluded that weight loss after bariatric surgery reduced the medical risks of obesity but psychosocial problems remain for many patients due to problems with excess skin [14]. These problems are important to bear in mind when discussing ways of improving levels of physical activity after bariatric surgery. Another thing to pay attention to is the fact that patients found it expensive to go to training facilities. An inexpensive alternative could be a home centered individualized physical fitness program. Tumaiti et al. [15] has showed that it is possible to motivate obese patients to improve cardiopulmonary fitness with at home centered physical fitness program that consisted of daily incremental physical activity i.e. walking and skeletal muscle resistance training [15]. Individualized home centered physical fitness programs needs to be evaluated for post bariatric-surgery patients.

Patients in this study expressed that physical activity is necessary for life satisfaction and that many things in life became easier due to improved work capacity. They also expressed a need to learn how to become more physically active and requested guidance in finding suitable levels of exercise. These findings are similar to a previous study regarding experiences of physical activity before bariatric surgery [7]. In the current and in the previous study patients experienced difficulties finding the right level of exercise.

The concepts of credibility, transferability and dependability are important in qualitative research and describe various aspects of trustworthiness [16]. We have described the process of analysis in detail and presented several quotations in the results to enhance the possibility for the reader to judge the trustworthiness of the study [17]. 
Yet the results reflect the experiences from this patient group the findings may differ in other post-bariatric groups. Patients had a very high BMI before surgery in our study making experiences not representative in patients with a lower BMI before surgery, making them less obese one year postoperatively. The result might also have been different in another cultural context.

It might be seen as a limitation that the whole interview focused on four domains. However our experience is that this enriched the results, as the patients often referred to physical activity in relation to other issues as e.g. quality of life and excess skin. There is a lack of studies in this area and we believe that more research is needed, studies that include longer follow-up periods and with patients with lower BMI prior to surgery. We also believe that more knowledge in this area could assist physical therapists in improving information and treatment for this patient group after bariatric surgery.

\section{IMPLICATIONS}

This study implies that patients experience both achievements but also specific hindrances one-year after bariatric surgery and probably need support to enhance physical activity. Physical therapists and other health care professionals should consider these when meeting postbariatric patients to make physical activity feasible.

\section{CONFLICT OF INTEREST}

The authors confirm that this article content has no conflict of interest.

\section{ACKNOWLEDGEMENTS}

Declared none.

\section{REFERENCES}

[1] Sjöström L. Bariatric surgery and reduction in morbidity and mortality: experiences from the SOS study. Int J Obes 2008; 32: S93-7.
[2] Egberts K, Brown WA, Brennan L, O'Brien PE. Does exercise improve weight loss after bariatric surgery? A systematic review. Obes Surg 2012; 22: 335-41.

[3] Hu G, Tuomilehto J, Silventoinen K, et al. The effects of physical activity and body mass index on cardiovascular, cancer and allcause mortality among 47212 middle-aged Finnish men and women. Int J Obes 2005; 29: 894-902.

[4] Eyre H, Kahn R, Robertson RM, et al. Preventing cancer, cardiovascular disease, and diabetes: a common agenda for the American Cancer Society, the American Diabetes Association, and the American Heart Association. CA: Cancer J Clin 2004; 54: 190207.

[5] WHO. The world health report 2002: reducing risks, promoting healthy life. Geneva: WHO 2002.

[6] World Confederation of Physical Therapy W. Description of Physical Therapy. World Confederation of Physical Therapy; 2011 [cited 27 May 2014]; Available from: http://www.wcpt.org/policy/ps-descriptionPT

[7] Wiklund M, Olsén MF, Willén C. Physical activity as viewed by adults with severe obesity, awaiting gastric bypass surgery. Physiother Res Int 2011; 16: 179-86.

[8] Søvik TT, Taha O, Aasheim ET, et al. Randomized clinical trial of laparoscopic gastric bypass versus laparoscopic duodenal switch for superobesity. Br J Surg 2010; 97: 160-6.

[9] Søvik TT, Aasheim ET, Taha O, et al. Weight loss, cardiovascular risk factors, and quality of life after gastric bypass and duodenal switch: a randomized trial. Ann Intern Med 2011; 155: 281-91.

[10] Caspersen CJ, Powell KE, Christenson GM. Physical activity, exercise, and physical fitness: definitions and distinctions for health-related research. Public Health Rep 1985; 100: 126-31.

[11] Hsieh HF, Shannon SE. Three approaches to qualitative content analysis. Qual Health Res 2005; 15: 1277-88.

[12] Krippendorff K. Content analysis: An introduction to its methodology. $2^{\text {nd }}$ ed. Thousand Oaks, California: Sage Publications, Inc. 2004.

[13] Erlichman J, Kerbey AL, James WPT. Physical activity and its impact on health outcomes. Paper 1: the impact of physical activity on cardiovascular disease and all-cause mortality: an historical perspective. Obes Rev 2002; 3: 257-71.

[14] Biörserud C, Olbers T, Fagevik Olsén M. Patients experience of surplus skin after laparoscopic gastric bypass. Obes Surg 2011; 21: 273-7.

[15] Tumiati R, Mazzoni G, Crisafulli E, et al. Home-centred physical fitness programme in morbidly obese individuals: a randomized controlled trial. Clin Rehabil 2008; 22: 940-50.

[16] Patton MQ. Qualitative research and evaluation methods. Thousand Oaks, California: Sage Publications, Inc. 2002.

[17] Graneheim UH, Lundman B. Qualitative content analysis in nursing research: concepts, procedures and measures to achieve trustworthiness. Nurse Educ Today 2004; 24: 105-12.

(c) Wiklund et al.; Licensee Bentham Open.

This is an open access article licensed under the terms of the Creative Commons Attribution Non-Commercial License (http://creativecommons.org/licenses/by-nc/3.0/) which permits unrestricted, non-commercial use, distribution and reproduction in any medium, provided the work is properly cited. 